\title{
Calagem em solos de várzea e a disponibilidade de nutrientes na solução do solo após $o$ alagamento
}

\author{
Liming in lowland soils and nutrient availability in soil solution after flooding
}

Leandro Souza da Silva' ${ }^{1}$ Sidnei Küster Ranno ${ }^{2}$

\section{RESUMO}

A calagem do solo altera o $\mathrm{pH}$ e, conseqüentemente, influencia no processo de redução dos solos submetidos ao alagamento para o cultivo do arroz irrigado, alterando a disponibilidade de nutrientes na solução do solo. Entretanto, a recomendação de calcário para o arroz irrigado é variável, implicando em diferentes quantidades a aplicar, dependendo da situação. Assim, o objetivo deste trabalho foi avaliar a liberação de nutrientes para a solução do solo após o alagamento, em três solos de várzea com diferentes valores de $\mathrm{pH}$, resultantes da aplicação de diferentes quantidades de calcário. Amostras de solos de várzea foram coletadas da camada de 0 a $20 \mathrm{~cm} \mathrm{em}$ áreas de produção de arroz nos municípios de Cachoeirinha/RS (Gleissolo), Faxinal do Soturno (Planossolo 1) e Santa Maria (Planossolo 2), as quais foram misturadas com calcário para comporem os seguintes tratamentos: zero; $1 / 2$ SMP e 1 SMP para pH 5,5 e 1 SMP para pH 6,0. Após 90 dias de incubação, as amostras foram acondicionadas em vasos plásticos com um dispositivo para coleta da solução do solo e alagadas. Aos 2, 8, $15,22,28,42$ e 56 dias de alagamento foram retiradas amostras da solução do solo e determinados os teores de Fe, Ca, $\mathrm{Mg}, \mathrm{Ke}$ $P$. Com os maiores valores de $\mathrm{pH}$, diminuíram os teores de ferro na solução, aumentaram os de cálcio e magnésio e não afetaram os teores de fósforo e potássio. As concentrações dos nutrientes e as mudanças provocadas pela calagem foram diferentes nos três solos.

Palavras chave: arroz, calcário, solos de várzea, liberação de nutrientes.

\section{ABSTRACT}

Liming changes soil $\mathrm{pH}$, reduction process and nutrient availability in flooded soils used for rice production. However, the lime requirement for rice production is variable, depending on the situation. The objective of the experiment was to evaluate the nutrient release to soil solution after flooding of three lowland soils with different $\mathrm{pH}$ values resulting from different lime application. Soils samples from 0 to $20 \mathrm{~cm}$ were collected in three places and mixed with different lime quantities: zero, $1 / 2$ SMP to $p H 5,5 ; 1$ SMP to $p H 5,5$; and 1 SMP to $p H$ 6,0. After 90 days of incubation, the samples were placed in plastic pots with a soil solution collector. After flooding, soil solution was collected at 2, 8, 15, 22, 28, 42 and 56 days and Fe, Ca, $\mathrm{Mg}$, K e P concentrations were analyzed. After flooding, the Fe concentration was reduced, the Ca and Mg were increased, and the $K$ and $P$ concentrations were not changed by lime rates. The soil solution nutrient concentrations after liming were different among the three soils types.

Key words: flooded rice, liming, lowland soils and nutrient release.

\section{INTRODUÇÃO}

Os problemas de um solo ácido estão relacionados com a menor disponibilidade de alguns nutrientes e, principalmente, com a ocorrência de toxidez de $\mathrm{Al}^{+3}$, cuja severidade é dependente do valor de $\mathrm{pH}$, mas se torna praticamente nula acima de valores de pH 5,5 (FOY, 1974). A neutralização da acidez do solo é realizada pela aplicação de um produto corretivo, normalmente o calcário. Por ser composto de carbonatos de cálcio e de magnésio, o calcário também tem efeito fertilizante com relação a esses dois nutrientes. Assim, a elevação do $\mathrm{pH}$, através da aplicação de calcário, é uma prática recomendada em solos ácidos para que sejam dadas condições adequadas ao desenvolvimento das plantas sensíveis à acidez (CFS RS/SC, 1994). Entretanto, em solos de várzea, cultivados principalmente com arroz irrigado

${ }^{1}$ Departamento de Solos, Centro de Ciências Rural, Universidade Federal de Santa Maria, 97105-900, Santa Maria, RS, Brasil. Email: leandro@smail.ufsm.br

${ }^{2}$ Fundação MS para Pesquisa e Difusão de Tecnologias Agropecuárias, Maracaju, MS, Brasil. 
por inundação, o pH e a disponibilidade de nutrientes ou de elementos tóxicos apresentam algumas peculiaridades, fundamentais para o estabelecimento de decisões quanto à prática da calagem.

Os solos de várzea apresentam como principal característica uma drenagem natural deficiente (hidromorfismo), ocasionado pelo relevo predominantemente plano, freqüentemente associado a uma camada subsuperficial impermeável e uma camada superficial rasa, com fertilidade natural média a baixa (PINTO et al., 1999). Essas características dificultam sua utilização com agricultura diversificada e favorecem o desenvolvimento da cultura do arroz irrigado por alagamento, graças à sua adaptação a essas condições do ambiente. Durante o alagamento do solo, o oxigênio molecular é consumido pelos microrganismos aeróbios, os quais são substituídos pelos anaeróbios, ocasionando um ambiente de redução e acúmulo de $\mathrm{CO}_{2}$ (PONNAMPERUMA, 1972). Assim, duas forças atuam sobre o $\mathrm{pH}$ do solo alagado em sentidos opostos. $\mathrm{O}$ acúmulo de $\mathrm{CO}_{2}$ diminui o pH pelo equilíbrio da reação: $\mathrm{CO}_{2}+\mathrm{H}_{2} \mathrm{O}$ $\leftrightarrow \mathrm{H}^{+}+\mathrm{HCO}_{3}^{-}$, e a redução de compostos oxidados eleva o $\mathrm{pH}$ pelo consumo de prótons no processo, exemplificado para os óxidos de ferro: $\mathrm{Fe}(\mathrm{OH})_{3}+2 \mathrm{H}^{+}$ $+2 \mathrm{e}-\leftrightarrow \mathrm{Fe}^{2+}+3 \mathrm{H}_{2} \mathrm{O}$ (VAHL \& LOPES, 1998). De maneira geral, o alagamento do solo causa um aumento no $\mathrm{pH}$ até valores próximos a 6,0, permanecendo estável a partir de 30 dias após o alagamento. Além da elevação natural do $\mathrm{pH}$, a solubilização de óxidos de ferro libera íons $\mathrm{Fe}^{2+}$ para a solução do solo, aumentando sua concentração. Neste processo, uma parte do fósforo adsorvido também é liberada, o que pode aumentar sua concentração na solução do solo. Embora o Ca, o Mg e o K não estejam diretamente envolvidos no processo de redução, o maior teor de $\mathrm{Fe}^{2+}$ na solução do solo pode deslocar parte desses cátions que estavam adsorvidos na fase sólida, aumentando sua disponibilidade para as plantas (VAHL, 1991).

Considerando as mudanças que ocorrem devido ao alagamento do solo, a calagem para o arroz irrigado está relacionada ao manejo da água de irrigação e à disponibilidade de cálcio e de magnésio no solo. Segundo a CQFS RS/SC (2004) e SOSBAI (2003), recomenda-se calcário para a cultura do arroz irrigado, no caso de sistemas de semeadura em solo seco, para atenuar os efeitos da acidez no período em que as plantas permanecem no solo sem o alagamento, quando então se utiliza o pH em água abaixo de 5,5 como critério para tomada de decisão de aplicar o calcário e o índice SMP para pH 5,5 como critério para estabelecer a dose de calcário. No caso de cultivo no sistema pré-germinado e transplante de mudas, onde o alagamento ocorre antes da semeadura e a elevação natural do $\mathrm{pH}$ coincide com a maior parte do ciclo da cultura, a calagem do solo não é recomendada para eliminar a acidez. Entretanto, independentemente do sistema de cultivo empregado, também se pode utilizar o calcário como fonte de Ca e de $\mathrm{Mg}$, ou seja, quando a análise de solo indicar valores de Ca menores do que 2,0 $\mathrm{cmol}_{\mathrm{c}} \mathrm{dm}^{-3}$ e/ou $\mathrm{Mg}$ menores do que $0,5 \mathrm{cmol}_{c} \mathrm{dm}^{-3}$ é recomendado uma tonelada de calcário por hectare (PRNT 100\%). Além disso, entre as práticas de manejo recomendadas para as áreas com toxidez de ferro está a calagem do solo até pH 6,0 (SOSBAI, 2003), apesar de ainda não existirem critérios definitivos no sistema de recomendação de corretivos para esta finalidade.

Dessa forma, existem diferentes critérios para estabelecer a dose de calcário a ser aplicado para a cultura do arroz irrigado, mas são poucos os experimentos que buscam relacionar a prática da calagem de solos de várzea com a disponibilidade de nutrientes essenciais ou tóxicos ao arroz irrigado por inundação. O objetivo deste trabalho foi avaliar a liberação de ferro e de outros nutrientes pelo alagamento, em três solos de várzea, com diferentes valores de $\mathrm{pH}$, resultantes da aplicação de diferentes quantidades de calcário estabelecidas pelo método SMP.

\section{MATERIAL E MÉTODOS}

Foi instalado um experimento em casa-devegetação no Departamento de Solos da Universidade Federal de Santa Maria, localizada no município de Santa Maria (RS). Utilizaram-se amostras de três solos representativos das áreas de produção de arroz do RS, localizados nos municípios de Faxinal do Soturno (Planossolo 1), Cachoeirinha (Gleissolo) e Santa Maria (Planossolo 2), as quais foram coletadas da camada de 0 a $20 \mathrm{~cm}$, secas ao ar e na sombra e peneiradas em malha de $4 \mathrm{~mm}$. Uma alíquota de cada solo foi moída a 2mm e utilizada para caracterização química inicial, conforme metodologias descritas em TEDESCO et al. (1995) (Tabela 1).

Os tratamentos aplicados foram níveis de calcário estabelecidos como 0; 1/2 SMP e 1 SMP para pH 5,5 e 1 SMP para pH 6,0 em cada solo, utilizandose calcário dolomítico (PRNT 75\%), segundo os resultados da análise dos solos e os critérios de calagem estabelecidos pela CFS RS/SC (1994). As amostras de solo foram misturadas ao calcário, umedecidas até $70 \%$ da capacidade de campo e mantidas em recipientes plásticos para incubação por 
Tabela 1 - Características químicas e teor de argila dos solos

\begin{tabular}{lccc}
\hline \multirow{2}{*}{ Parâmetro } & \multicolumn{3}{c}{ Solos } \\
\cline { 2 - 4 } & $\begin{array}{c}\text { Planossolo } \\
\text { Hidromórfico 1 }\end{array}$ & $\begin{array}{c}\text { Gleissolo } \\
\text { Háplico }\end{array}$ & $\begin{array}{c}\text { Planossolo } \\
\text { Hidromórfico 2 }\end{array}$ \\
\hline pH água (1:1) & 5,1 & 4,6 & 4,8 \\
Índice SMP & 6,5 & 5,7 & 5,6 \\
Argila $\left(\mathrm{g} \mathrm{kg}^{-1}\right)$ & 40 & 90 & 150 \\
Carbono $\left(\mathrm{g} \mathrm{kg}^{-1}\right)$ & 7,0 & 14 & 6,0 \\
Ca $\left(\mathrm{cmol}_{\mathrm{c}} \mathrm{kg}^{-1}\right)^{1}$ & 1,9 & 1,7 & 3,8 \\
$\mathrm{Mg}\left(\mathrm{cmol}_{\mathrm{c}} \mathrm{kg}^{-1}\right)^{1}$ & 0,26 & 0,35 & 1,50 \\
$\mathrm{Al}\left(\mathrm{cmol}_{\mathrm{c}} \mathrm{kg}^{-1}\right)^{1}$ & 0,6 & 1,0 & 1,4 \\
$\mathrm{P}\left(\mathrm{mg} \mathrm{kg}^{-1}\right)^{2}$ & 10,6 & 13,9 & 7,5 \\
$\mathrm{~K} \mathrm{(mg} \mathrm{kg})^{-1}$ & 30 & 34 & 22 \\
\hline
\end{tabular}

${ }^{1}$ Extraídos com solução KCl 1 M

${ }^{2}$ Extraídos com solução Mehlich-I

um período de 90 dias. A cada 15 dias, os solos foram revolvidos para dissipar o $\mathrm{CO}_{2}$ liberado pela reação do calcário e a umidade reposta até o nível determinado.

Após 90 dias da aplicação do calcário, as amostras foram caracterizadas quanto ao pH em água, índice SMP e os teores de $\mathrm{Ca}, \mathrm{Mg}, \mathrm{K}$ e Al trocáveis (TEDESCO et al., 1995) (Tabela 2). Posteriormente, uma alíquota de $4 \mathrm{~kg}$ de cada tratamento foi colocada em vasos plásticos de 8 litros com um dispositivo de PVC para a retirada da solução do solo aos $5 \mathrm{~cm}$ de profundidade, semelhante ao utilizado por SILVA et al. (2000). Os solos foram alagados com a aplicação de uma lâmina de água de aproximadamente $5 \mathrm{~cm}$ e mantidos em casa de vegetação por 60 dias, submetidos à variação de temperatura inerente ao período de dezembro de 2002 a fevereiro de 2003. O delineamento experimental foi completamente casualizado com 4 repetições.

Aos 2, 8, 15, 22, 28, 42, 56 dias de alagamento foram retiradas amostras da solução do solo, as quais foram filtradas em filtro milipore $0,45 \mu \mathrm{m}$ e acidificadas com $\mathrm{HCl} 2 \mathrm{~mol} \mathrm{~L}^{-1}$ até $\mathrm{pH}$ 1,0. Nestas amostras, foram determinados os teores de Fe, Ca e Mg por absorção atômica, K por fotometria de chama e $\mathrm{P}$ por colorimetria, este de acordo com o método de MURPHY \& RILEY (1962). Após análise da variância $(\mathrm{P}<0,05)$, as médias dos tratamentos foram comparadas pelo teste de Tukey $(\mathrm{P}<0,05)$, considerando um esquema fatorial 3 solos $\mathrm{x} 4$ níveis de calcário $\mathrm{x} 7$ épocas de coleta.

\section{RESULTADOS E DISCUSSÃO}

Os teores de ferro aumentaram durante o alagamento no Planossolo 1 e no Gleissolo até atingirem um pico aos 22 dias de alagamento, respectivamente, diminuindo para valores estáveis (Figura 1). Já o Planossolo 2 apresentou um aumento constante dos teores de ferro da solução, o que demonstra a necessidade de um período maior de alagamento para atingir o equilíbrio neste solo, comparado com os anteriores. Esse aumento nos teores de ferro da solução do solo se deve à redução dos óxidos de ferro e a posterior diminuição deve-se ao

Tabela 2 - Características químicas dos solos 90 dias após aplicação dos tratamentos e da incubação

\begin{tabular}{|c|c|c|c|c|c|c|c|}
\hline \multirow{2}{*}{ Solo } & \multirow{2}{*}{ Tratamento } & \multirow{2}{*}{$\begin{array}{l}\text { Dose de } \\
\text { calcário }^{1}\end{array}$} & \multirow{2}{*}{$\begin{array}{c}\mathrm{pH} \\
\text { água }\end{array}$} & \multirow{2}{*}{$\begin{array}{l}\text { índice } \\
\text { SMP }\end{array}$} & \multicolumn{3}{|c|}{ Cátions trocáveis } \\
\hline & & & & & $\mathrm{Ca}^{2}$ & $\mathrm{Mg}^{2}$ & $\mathrm{Al}^{2}$ \\
\hline \multirow{5}{*}{$\begin{array}{l}\text { Planossolo } 1 \\
\text { (Faxinal do Soturno/RS) }\end{array}$} & & $\mathrm{Mg} \mathrm{ha}^{-1}$ & & \multicolumn{4}{|c|}{ 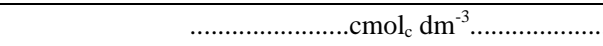 } \\
\hline & Testemunha & 0,0 & 4,5 & 6,4 & 1,8 & 0,14 & 0,82 \\
\hline & 1/2 SMP 5,5 & 0,2 & 4,7 & 6,5 & 1,6 & 0,15 & 0,62 \\
\hline & 1 SMP 5,5 & 0,4 & 4,7 & 6,3 & 1,7 & 0,18 & 0,55 \\
\hline & 1 SMP 6,0 & 1,1 & 4,9 & 6,6 & 1,8 & 0,24 & 0,30 \\
\hline \multirow{4}{*}{$\begin{array}{l}\text { Gleissolo } \\
\text { (Cachoeirinha/RS) }\end{array}$} & Testemunha & 0,0 & 4,4 & 5,5 & 0,9 & 0,10 & 1,26 \\
\hline & 1/2 SMP 5,5 & 1,4 & 4,9 & 5,9 & 1,5 & 0,33 & 0,37 \\
\hline & 1 SMP 5,5 & 2,8 & 5,2 & 6,1 & 2,2 & 0,57 & 0,10 \\
\hline & 1 SMP 6,0 & 4,8 & 5,6 & 6,3 & 2,8 & 0,82 & 0,00 \\
\hline \multirow{4}{*}{$\begin{array}{l}\text { Planossolo } 2 \\
\text { (Santa Maria/RS) }\end{array}$} & Testemunha & 0,0 & 4,5 & 5,6 & 2,9 & 0,58 & 1,41 \\
\hline & 1/2 SMP 5,5 & 1,6 & 4,9 & 6,0 & 3,6 & 0,86 & 0,50 \\
\hline & 1 SMP 5,5 & 3,2 & 5,4 & 6,4 & 4,0 & 1,06 & 0,00 \\
\hline & 1 SMP 6,0 & 5,4 & 5,7 & 6,5 & 4,6 & 1,30 & 0,00 \\
\hline
\end{tabular}

${ }^{1}$ Considerando PRNT 100\%

${ }^{2}$ Extraídos com solução $\mathrm{KCl} 1 \mathrm{M}$

Ciência Rural, v. 35, n. 5, set-out, 2005. 


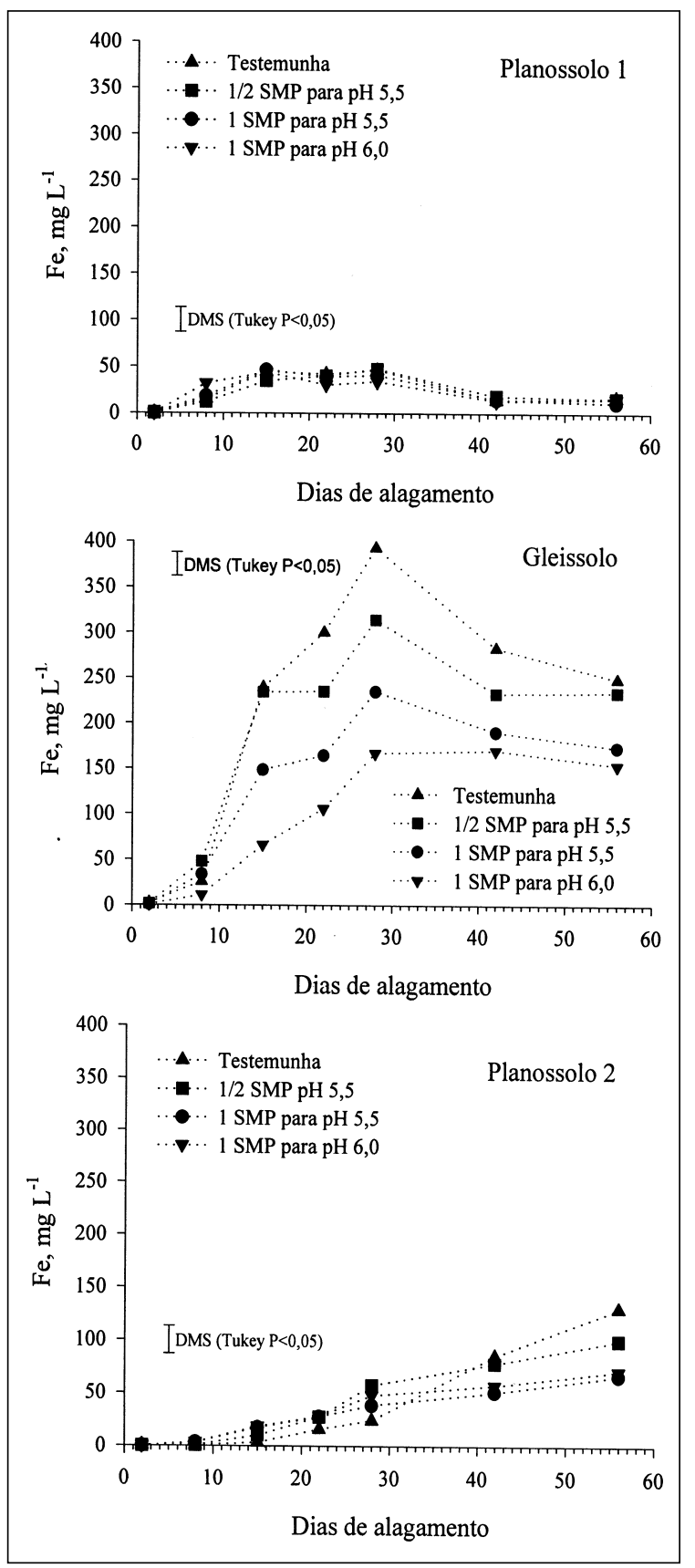

Figura 1 - Teores de ferro na solução do solo (mg L $\left.{ }^{-1}\right)$ em três solos de várzea (Planossolo 1, Gleissolo e Planossolo 2), em função de doses de calcário e tempo de alagamento.

aumento do $\mathrm{pH}$, que diminui a solubilidade dos compostos de ferro. Para o Planossolo 1, as quantidades de ferro liberadas foram baixas (menores que $\left.50 \mathrm{mg} \mathrm{L}^{-1}\right)$ e não se verificou diferença $(\mathrm{p}<0,05)$ entre os tratamentos para este solo. Esse comportamento pode ser associado com os valores de pH em água do solo, que pouco variaram após a incubação com o corretivo (Tabela 2), demonstrando que o índice SMP não foi eficiente para estimar a necessidade de calcário desse solo. Uma alternativa para esta situação seria utilizar equações baseadas nos teores de matéria orgânica e alumínio para solos pouco tamponados, conforme preconizado pela CFS RS/SC (1994).

Apesar de o ferro ser um nutriente essencial às plantas, seu teor na solução do solo pode atingir níveis tóxicos ao arroz. Segundo SOUSA et al. (2000), a toxidez por ferro já foi constatada em lavouras de praticamente todos os estados produtores de arroz irrigado no Brasil e que, no RS, não existindo informações a respeito da ocorrência de toxidez por ferro até fins da década de 70, quando predominavam cultivares do tipo tradicional ou intermediário. Com o surgimento dos cultivares modernos, a partir da década de 80 , os sintomas de toxidez por ferro passaram a ser observados com maior freqüência. Em levantamento feito na década de 80 no RS, LOPES (1987) relata que 95\% dos municípios arrozeiros apresentaram cultivos com toxidez de ferro, com maior intensidade nas regiões da Campanha e Fronteira Oeste. Este cenário foi parcialmente transformado com o surgimento de cultivares com alguma tolerância à toxidez por ferro a partir da década de 90, mas o problema ainda persiste com maior ou menor intensidade em todas as regiões.

O Gleissolo foi o que demonstrou a maior liberação de ferro, atingindo concentrações mais elevadas (392mg $\mathrm{L}^{-1}$ na testemunha), mesmo quando se aplicou a maior dose de calcário $\left(170 \mathrm{mg} \mathrm{L}^{-1}\right)$. Para este solo, verificou-se efeito $(\mathrm{p}<0,05)$ da calagem sobre redução do teor de ferro na solução, principalmente na dose para elevar o pH até 6,0. No Planossolo 2, os teores de ferro atingiram níveis intermediários entre os solos estudados (130mg L $\mathrm{L}^{-1}$ na testemunha), mas os valores não se estabilizaram. Este comportamento pode estar associado à presença de outros compostos passíveis de serem reduzidos na seqüência preferencial de oxirredução, como o nitrato e os óxidos de manganês (SOUSA et al., 2000), retardando o processo de liberação de ferro para a solução do solo. Revisando vários trabalhos, esses autores encontraram teores de ferro, considerados como críticos para ocorrência de toxidez de ferro, variáveis entre 30 e 500 $\mathrm{mg} \mathrm{L}^{-1}$. Já, FAGERIA et al. (1981), cultivando arroz (cultivar IAC 435) em solução nutritiva, citam que a toxicidade ocorreu em concentrações acima de $80 \mathrm{mg} \mathrm{L}^{-1}$. Desta forma, se forem levados em conta os dados relatados, observase, na solução do Gleissolo, concentrações de ferro bastante superiores às consideradas tóxicas por 
FAGERIA et al. (1981), mesmo corrigindo-se a acidez pelo uso do calcário segundo o SMP para pH 6,0. Isto indica que a calagem, com o objetivo de consumir $\mathrm{H}^{+}$ e diminuir a intensidade de redução de ferro, pode não ser isoladamente uma ferramenta eficiente para eliminar todos os efeitos da toxidez de ferro às plantas. Isto explica por que alguns grupos de solos parecem ser mais propensos à ocorrência de toxidez por ferro; no entanto, é muito difícil estabelecer as condições necessárias para a sua ocorrência, devido aos outros fatores envolvidos no processo (SOUSA et al., 2000).

A concentração de cálcio na solução do Gleissolo aumentou até atingir um valor máximo aos 28 dias de alagamento, a partir do qual se verificou uma pequena redução nos teores até a estabilidade, dependendo da dose de calcário adicionada em cada tratamento (Figura 2). O Planossolo 1 apresentou um valor máximo aos 22 dias de alagamento, atingindo teores mais baixos do que o Gleissolo. No Planossolo 2, o teor de cálcio aumentou até os 56 dias de alagamento e ainda não atingiu um valor máximo, o que pode ser atribuído à não estabilidade do processo de redução do ferro e o cálcio ainda estar sendo deslocado dos sítios de troca por aquele elemento. $\mathrm{O}$ cálcio pode apresentar um efeito importante sobre a inibição da absorção de $\mathrm{K}^{+}$por $\mathrm{Fe}^{2+}$, pois o mesmo atua na estrutura da membrana celular, mantendo sua integridade, e nos carregadores, mantendo a configuração adequada para a absorção, podendo controlar as inibições de natureza competitiva e nãocompetitiva (VAHL, 1991 e VAHL \& LOPES, 1998). Dessa forma, a maior disponibilidade de cálcio pode contribuir para amenizar os problemas de toxidez por ferro, mesmo quando os níveis deste elemento na solução do solo são elevados. O magnésio, embora atingindo menores teores comparados ao cálcio, teve comportamento semelhante nos três solos (Figura 2), fato atribuído à similaridade química dos elementos e à adição de calcário dolomítico como corretivo da acidez, o que proporciona uma adição destes elementos em uma relação constante dentro das doses aplicadas.

Os teores de fósforo e de potássio foram bastante distintos nos três solos, mas não foram afetados pelos tratamentos com calagem ao longo do período de alagamento (Figura 3). Esperava-se que a aplicação de calcário, ao promover a elevação do pH e aumento das quantidades de Ca e Mg trocável, alterando o curso da redução do solo através do consumo de $\mathrm{H}^{+}$necessários para a redução dos óxidos de ferro, modificasse a quantidade de ferro liberada e a dinâmica dos outros nutrientes direta ou indiretamente afetados pela redução. As diferenças entre os solos baseiam-se em diferenças eletroquímicas inerentes da composição de cada solo, as quais foram determinantes para estabelecer o comportamento destes nutrientes na solução. No Planossolo 1 e no Gleissolo, houve um aumento nos teores de fósforo com o tempo de alagamento, o que era esperado em função do decorrer do processo de redução do ferro e a conseqüente liberação do fósforo adsorvido. Já no Planossolo 2, não se observa uma alteração significativa nos teores de fósforo da solução solo com o alagamento, pois é provável que a cinética de liberação do fósforo seja menor do que a cinética de sua readsorção ao solo, fazendo com que o teor de fósforo na solução mantenha-se baixo (GONÇALVES, 2003). Em relação ao teor de potássio, enquanto no Planossolo 1, os teores ficaram em torno de $10 \mathrm{mg} \mathrm{L}^{-1} \mathrm{e}$, no Gleissolo, estabilizou em torno de $5 \mathrm{mg} \mathrm{L}^{-1}$, o Planossolo 2 estabilizou em torno de $2 \mathrm{mg} \mathrm{L}^{-1}$ (Figura 3 ), diferenças que podem ser associadas as características eletroquímicas da superfície em relação às cargas de adsorção não específica e a disponibilidade dos demais nutrientes que competem com o potássio por essas cargas em cada solo.

Os principais mecanismos envolvidos nos efeitos do calcário sobre a toxidez de ferro são o consumo dos $\mathrm{H}^{+}$necessários para a redução dos óxidos de ferro, o que deve diminuir a quantidade de ferro liberada, e o aumento das quantidades de Ca e Mg na solução do solo. Os efeitos da calagem sobre os teores de cálcio, magnésio e potássio têm reflexos importantes sobre a ocorrência de toxidez por ferro. Segundo MOORE \& PATRICK (1989), a competição entre os cátions pelos sítios de absorção nas raízes tem grande influência sobre a absorção do ferro e, conseqüentemente, sobre possibilidade de ocorrência da toxidez. Os autores observaram que a absorção do ferro pelo arroz correlacionou-se com um índice resultante da razão entre a concentração de $\mathrm{Fe}^{2+}$ e a soma dos catións divalentes na solução do solo $\left(\mathrm{Fe}^{2+} /\right.$ $\left.\mathrm{Fe}^{2+}+\mathrm{Mn}^{2+}+\mathrm{Ca}^{2+}+\mathrm{Mg}^{2+}\right)$ e foi excessiva a partir do valor 0,75 desse índice, ou seja, quando a concentração de $\mathrm{Fe}^{2+}$ na solução do solo foi superior a $75 \%$ do total dos cátions divalentes presentes. Dessa forma, o aumento da disponibilidade de cálcio e magnésio na solução do solo concomitantemente com a redução na disponibilidade de ferro provocados pela calagem do solo contribui para um ambiente menos favorável à ocorrência da toxidez por ferro, mesmo quando os teores deste elemento na solução permanecem elevados.

Segundo VAHL (1999), embora a recomendação de calcário para o arroz preconize elevar o pH até 5,5, em áreas onde ocorrem sintomas de toxidez de ferro seria recomendável utilizar calcário 


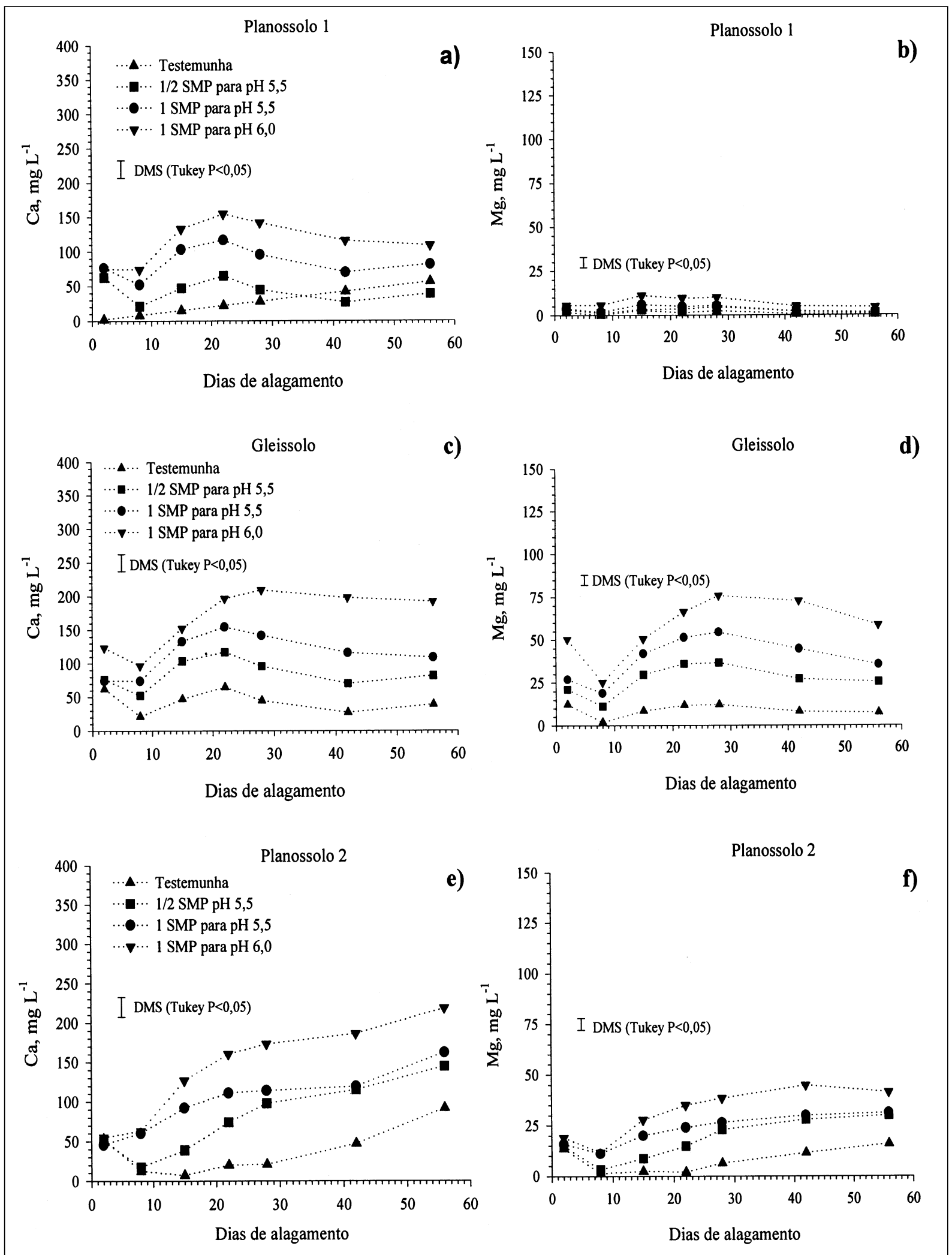

Figura 2 - Teores de cálcio (a, c, e) e de magnésio (b,d,f) na solução do solo $\left(\mathrm{mg} \mathrm{L}^{-1}\right)$ em três solos três solos de várzea (Planossolo 1 , Gleissolo e Planossolo 2) em função de doses de calcário e tempo de alagamento.

Ciência Rural, v.35 n. 5, set-out, 2005. 

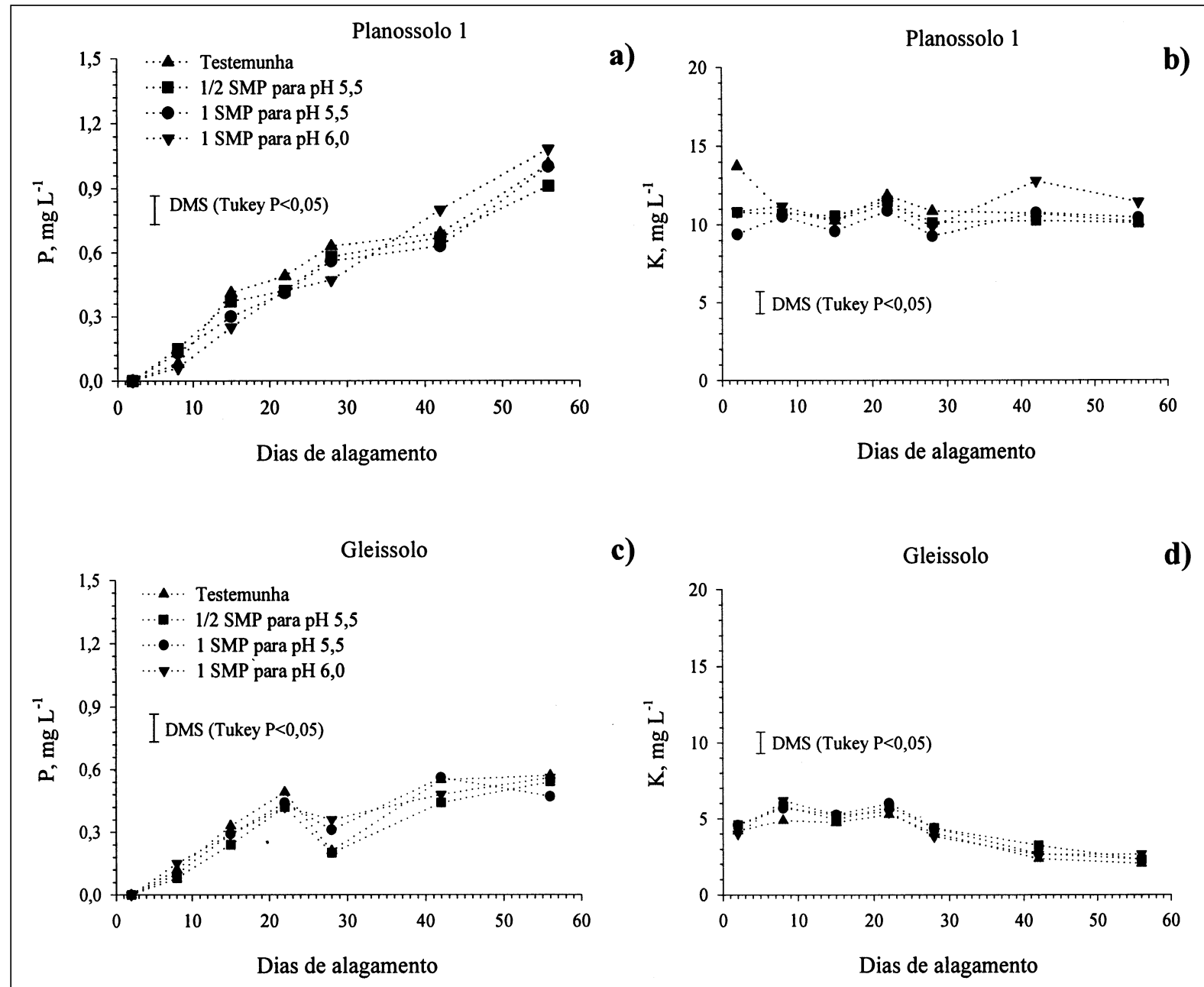

c)

Gleissolo

d)
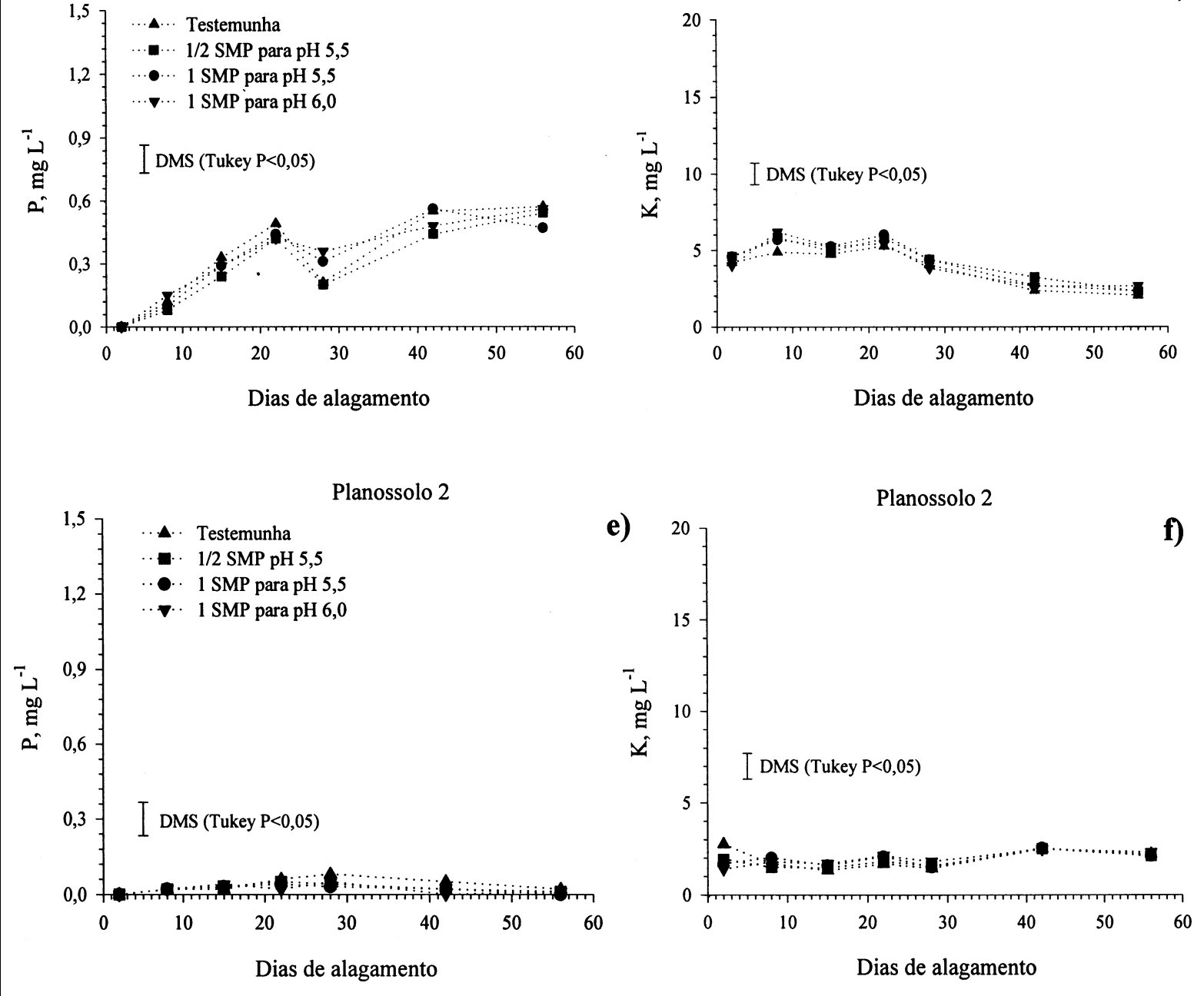

Figura 3 - Teores de fósforo (a, c, e) e de potássio (b,d,f) na solução do solo (mg L $\left.\mathrm{L}^{-1}\right)$ em três solos de várzea (Planossolo 1, Gleissolo e Planossolo 2) em função de doses de calcário e tempo de alagamento.

Ciência Rural, v. 35, n. 5, set-out, 2005. 
para elevar o pH a 6,0. Entretanto, nem sempre a cultura do arroz responde à prática da calagem (FAGERIA et al., 1977; PATRA \& MOHANTY, 1994; VIELEWICKI, 1998), o que pode estar relacionado com a ausência de alumínio em níveis tóxicos mesmo em $\mathrm{pH}$ abaixo de 5,5, e/ou a elevação natural do pH com o alagamento antes que ocorram danos à cultura, eliminando o alumínio tóxico e alterando a disponibilidade dos nutrientes.

\section{CONCLUSÕES}

A prática da calagem, utilizando o índice SMP para estimar a dose de calcário, diminuiu a liberação de ferro no solo alagado em algumas condições, mas sempre aumentou a disponibilidade de cálcio e magnésio na solução do solo. Nestes casos, os efeitos dependeram do tipo de solo e foram proporcionais às doses aplicadas.

Os teores de fósforo e de potássio na solução do solo não foram afetados pela prática da calagem nos solos e nas doses de calcário aplicadas.

\section{REFERÊNCIAS}

COMISSÃO DE FERTILIDADE DO SOLO - RS/SC. Recomendações de adubação e calagem para os estados do Rio Grande do Sul e Santa Catarina. 3.ed. Passo Fundo: SBCS-NRS/EMBRAPA-CNPT, 1994. 224p.

COMISSÃO DE QUÍMICA E FERTILIDADE DO SOLO - RS/ SC. Manual de adubação e calagem para os estados do Rio Grande do Sul e Santa Catarina. Porto Alegre : SBCS-NRS/ EMBRAPA-CNPT, 2004. 400p.

FAGERIA, N.K. et al. Resposta do arroz irrigado à aplicação de fósforo, zinco e calcário. Revista Brasileira de Ciência do Solo, Campinas, v.1, p.72-76, 1977.

FAGERIA, N.K. et al. Influências do ferro no crescimento e na absorção de $\mathrm{P}, \mathrm{K}$, Ca e $\mathrm{Mg}$ pela planta de arroz em solução nutritiva. Pesquisa Agropecuária Brasileira, Brasília, v.16, n.4, p.483-488, 1981.

FOY, E.D. Effects of aluminum on plant growth. In: THE PLANT ROOT AND ITS ENVIRONMENT, 1974, Charlottesville. Anais... Charlottesville : University of Virginia, 1974. p.601-642.

GONÇALVES, G.K. Solubilização de fosfatos naturais em solos alagados. 2003. 49f. Dissertação (Mestrado em Ciências) - Curso de Pós-graduação em Agronomia, Universidade Federal de Pelotas.

LOPES, M.S. Resultados obtidos em estudos com ferro no IRGA. In: BARBOSA FILHO, M.P. (Coord). REUNIÃO
SOBRE FERRO EM SOLOS ALAGADOS, 1., 1987, Goiânia. Anais... Goiânia: Embrapa, 1987. p.170-179.

MURPHY, J.; RILEY, J.P. A modified single solution method for the determination of phosphate in natural waters. Analytica Chimica Acta, v.27, p.31-36, 1962.

MOORE, P.A.; PATRICK, W.H. Iron availability and uptake by rice in acid sulfate soils. Soil Science Society of America Journal, Madison, v.53, p.471-476, 1989.

PATRA, B.N.; MOHANTY, S.K. Effect of nutrients and liming on changes in $\mathrm{pH}$, redox potential, and uptake of iron and manganese by wetland rice in iron toxic soil. Biology and Fertility of Soils, Berlin, v.17, p.255-258. 1994.

PINTO, L.F.S. et al. Caracterização de solos de várzea. In: GOMES, A.S.; PAULETTO, E.A. (Eds). Manejo do solo e da água em áreas de várzea. Pelotas : Embrapa Clima Temperado, 1999. Cap.1, p.11-36.

PONNAMPERUMA, F.N. The chemical of submerged soils. Advances in Agronomy, v.24, p.29-96, 1972.

SILVA, L.S. et al. Dinâmica de ferro e potássio na solução de solo alagado em diferentes profundidades, na presença e ausência de plantas de arroz. In: REUNIÃO SUL BRASILEIRA DE CIÊNCIA DO SOLO, 3., 2000, Pelotas. Resumos... Pelotas: NRS/SBCS, 2000. CD-ROM.

SOSBAI. Sociedade Sul-brasileira de Arroz Irrigado. Arroz irrigado: recomendações técnicas da pesquisa para o Sul do Brasil. Balneário Camboriú : SOSBAI, 2003. 126p.

SOUSA, R.O. et al. Solos alagados. In. MEURER, E.J. (Ed). Fundamentos de química do solo. Porto Alegre : Gênesis, 2000. Cap.7, p.127-149.

TEDESCO, M.J. et al. Análise de solo, plantas e outros materiais. 2.ed. Porto Alegre : Departamento de Solos Universidade Federal do Rio Grande do Sul, 1995. 174 p. (Boletim Técnico 5).

VAHL, L.C. Toxidez de ferro em genótipos de arroz irrigado por alagamento. 1991. 173f. Tese (Doutorado em Agronomia) - Curso de Pós-graduação em Agronomia, Universidade Federal do Rio Grande do Sul.

VAHL, L.C. Fertilidade de solos de várzea. In: GOMES, A.S., PAULETTO, E.A., (Eds). Manejo do solo e da água em áreas de várzea. Pelotas: Embrapa Clima Temperado, 1999. p.119-162.

VAHL, L.C.; LOPES, S.I.G. Nutrição de plantas. In: PESQUE, S.T. et al. (Eds). Produção de arroz irrigado. Pelotas : UFPel, 1998. p.149-206.

WIELEWICKI, A.P. et al. Absorção de nutrientes pelo arroz em resposta a calagem e a época de início da irrigação. Ciência Rural, Santa Maria, v.28, n.1, p.17-21, 1998. 